\title{
Late diagnosis of celiac disease in an asymptomatic infant with growth failure
}

\author{
Mauro Bozzola1*, Elena Bozzola², Sara Pagani ${ }^{1}$, Amelia Mascolo $^{1}$, Rossella Porto ${ }^{1}$ and Cristina Meazza ${ }^{1}$
}

\begin{abstract}
The clinical spectrum for celiac disease (CD) is broad and includes cases with either typical (intestinal) or atypical (extraintestinal) features, often making the diagnosis of CD very difficult.

We describe the case of a girl presenting with stunted growth and malnourishment. She was evaluated at 14 months for decreased growth rate without any signs of gastrointestinal, renal or endocrine disorders. She was evaluated for CD, but resulted negative for anti-tTG antibodies.

At the age of 4.1 years, she exhibited basal dental enamel hypoplasia, iron deficiency anaemia despite repeated iron supplementation, with persistent reduced height ( -2.79 SDS), BMI (-0.76 SDS), growth velocity (-1.79 SDS) and delayed bone age (1.5 year). The CD screening was repeated and very high anti-tTG-lgA $(128 \mathrm{IU} / \mathrm{ml}$, normal values $<7 \mathrm{IU} / \mathrm{ml}$ ) and anti-tTG-lgG $(77 \mathrm{IU} / \mathrm{ml}$, normal values $<7 \mathrm{IU} / \mathrm{ml})$ values were found. HLA genotyping revealed an HLA DQ2 haplotype. A duodenal biopsy revealed severe villous atrophy with crypt hyperplasia and increased intraepithelial lymphocytes (> 40 IELs/100 epithelial cells) confirming the diagnosis of CD. A gluten-free diet was started and after only four months, her growth velocity increased from $4.83 \mathrm{~cm} /$ year $(-1.79 \mathrm{SDS})$ to $6.53 \mathrm{~cm} /$ year $(-0.15 \mathrm{SDS})$.

In conclusion, we report the development of a positive serology for CD in an asymptomatic child with growth retardation, who previously was investigated for $C D$ and resulted negative. Therefore, when faced with retarded growth in young patients, after excluding other malabsorption conditions and even when CD serological markers are negative, the paediatric endocrinologist should request HLA genotyping, before the intestinal biopsy, in order to check for the presence of risk alleles.
\end{abstract}

Keywords: Celiac disease, HLA, Malnourishment

\section{Background}

Celiac disease (CD) is an immune-mediated disease which is triggered by the ingestion of gliadin and other prolamines which are toxic in genetically susceptible subjects. The genetic risk factors for CD have been well characterized. In fact, more than $90 \%$ of patients share the major histocompatibility complex II class human leukocyte antigen (HLA)-DQ2 haplotype and most of the remaining subjects carry HLA-DQ8 [1,2]. Subjects negative for both HLA-DQ2 and -DQ8 are very unlikely to suffer from CD. Therefore, HLA genotyping is an important as exam for first degree relatives or as a supporting test when biopsy is excluded due to its invasive nature in symptomatic subjects with high antibody levels [3].

\footnotetext{
* Correspondence: mauro.bozzola@unipv.it

'Internal Medicine and Therapeutics Department, University of Pavia,

Fondazione IRCCS San Matteo, Pavia, Italy

Full list of author information is available at the end of the article
}

Occasionally, the diagnosis of $\mathrm{CD}$ can be difficult in patients in whom serological markers are absent. As suggested by the new ESPGHAN guidelines, if there is a strong suspicion of $\mathrm{CD}$, despite a negative serology, a small bowel biopsy has to be performed [3].

Here, we describe an asymptomatic child with stunted growth and negative serology, in whom $\mathrm{CD}$ was not diagnosed at the first evaluation, but later during the follow-up when she became seropositive for $\mathrm{CD}$.

\section{Case presentation}

A 4.1-year-old girl was referred to our department for failure to thrive and anorexia. She was born at term after an uneventful pregnancy with a weight of 3,230 g, a length of $52 \mathrm{~cm}$ and head circumference of $34.5 \mathrm{~cm}$. The perinatal period was normal and her Apgar score was 9 at $5 \mathrm{~min}$. She received formula from birth. Gluten was included for the first time at the age of seven months, without any 
adverse gastrointestinal effects. The target height of the girl was $163 \mathrm{~cm}(0.13$ SDS). Both parents are healthy and unrelated, and had normal development during puberty.

From the age of six months, she showed a progressive reduction in growth rate, both for weight and height, and at the age of 14 months, she was evaluated at another centre and showed short stature (cm 69.9, -2.19 standard score deviation, SDS) (Figure 1) with adequate weight $(7,520 \mathrm{Kg}$, body mass index (BMI) $-0.45 \mathrm{SDS}$ ), free thyroxin (FT4) and thyroid-stimulating hormone (TSH) were within the normal range. Furthermore, serum anti-transglutaminase (anti-tTG) antibodies were negative (IgA-tTG $1.7 \mathrm{IU} / \mathrm{ml}$ and IgG-tTG $7.2 \mathrm{IU} / \mathrm{ml}$; normal values $<7 \mathrm{IU} / \mathrm{ml}$ ) with normal for age circulating IgA values ( $38 \mathrm{mg} / 100 \mathrm{ml}$; normal values: $37-257 \mathrm{ng} / \mathrm{ml}$ ). She exhibited iron deficiency anaemia, but the sweat test $\left(\mathrm{Na}^{+} 16 \mathrm{mEq} / \mathrm{l}\right.$ and $\mathrm{Cl}^{-} 13 \mathrm{mEq} / \mathrm{l}$; normal values: $\mathrm{Na}^{+}$and $\mathrm{Cl}^{-}<40 \mathrm{mEq} / \mathrm{l}$ ) and peripheral $\mathrm{T}$ and $\mathrm{B}$ cell assessment resulted normal. No abnormalities of the kidneys were detected by ultrasound and no gastrointestinal disorders were reported.
At the moment of our evaluation, at the age of 4.1 years, physical examination revealed only basal dental enamel hypoplasia. She showed a height of $89.5 \mathrm{~cm}(-2.79 \mathrm{SDS})$ (Figure 1), a weight of $12,5 \mathrm{Kg}$ (BMI $-0.76 \mathrm{SDS}$ ), a delayed bone age of 1.5 years, and a growth velocity during the last year of $4.83 \mathrm{~cm} /$ year $(-1.79 \mathrm{SDS})$. Iron deficiency anaemia persisted despite cyclically repeated iron supplementation. The screening for $\mathrm{CD}$ was repeated and very high IgA -tTG $(128 \mathrm{IU} / \mathrm{ml})$ and IgG-tTG (77 IU/ $\mathrm{ml}$ ) values were observed. These data were highly suggestive of CD. HLA genotyping revealed DQA1*02:01, 05:05 and DQB1 *02:02, 03:01 haplotypes (i.e. HLA DQ2 haplotype). A duodenal biopsy revealed severe villous atrophy (Marsh 3c) with crypt hyperplasia and increased intraepithelial lymphocytes (> 40 IELs/100 epithelial cells) confirming the diagnosis of $\mathrm{CD}$. A gluten-free diet was started and after only four months her growth velocity increased from $4.83 \mathrm{~cm} /$ year $(-1.79 \mathrm{SDS})$ to $6.53 \mathrm{~cm} /$ year $(-0.15$ SDS $)$.

HLA genotyping in first-degree relatives revealed DQA1*05:01, 05:05 and DQB1*02:01, 03:01 in her older

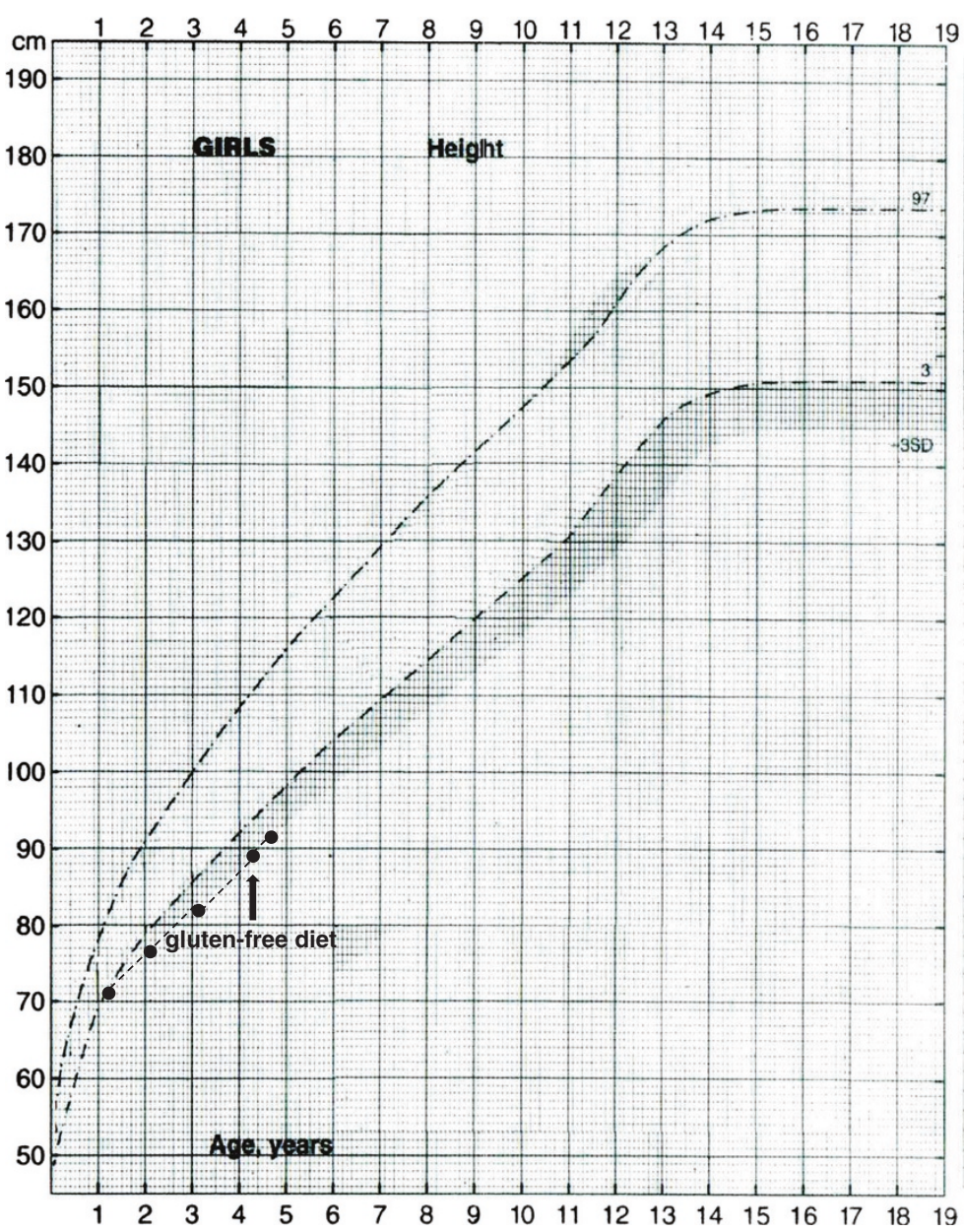

Figure 1 Height curve of the subject. The arrow indicates the start of the gluten-free diet. 
brother, who had a negative serology for $\mathrm{CD}$. Therefore, his diet includes gluten and he repeats CD serology testing every three years.

\section{Discussion}

Celiac disease is not simply a gastrointestinal condition, but an immune-mediated systemic disorder, strongly dependent on HLA-DQ2 and DQ8 haplotypes. At present, diagnosing $\mathrm{CD}$ is often difficult, due to the reduced prevalence of the classical form with gastrointestinal symptoms and the increased prevalence of atypical forms [4]. Clinical suspicion should be supported by positive serological tests and diagnosis requires typical histopathological findings with a biopsy of the small intestine, especially when the patient is asymptomatic [3]. It is important to stress that early diagnosis of $\mathrm{CD}$ with prompt initiation of a gluten-free diet can decrease the potential risk of both adenocarcinoma and lymphoma, which occurs more frequently in untreated celiac patients than in the general population [5].

This report emphasizes the difficulty of diagnosing CD in asymptomatic patients with a negative serology who exhibit only stunted growth. In fact, when this patient was first evaluated, she resulted negative for anti-tTG, her only symptom was progressive growth failure.

The negative serology observed in our patient at the 14th month of life could be related to the lower sensitivity of anti-tTG antibodies in children younger than two years, as recently described by Maglio et al. [6]. We did not measure antibodies against native gliadin (AGA) which is indicated in children up to two years old [7]. However, a recent study suggested that IgA-anti-tTG results are more reliable than AGA, also in younger children [8].

Then, interestingly after about a three year-follow-up, high serum levels of anti-tTG unexpectedly appeared in the absence of typical CD gastrointestinal features. Furthermore, the HLA genotyping showed one haplotype linked to $C D$ susceptibility. Interestingly, a different haplotype linked to $\mathrm{CD}$ susceptibility was found in her asymptomatic older brother who currently exhibits a negative serology. We may speculate that this difference is due to a different gene dose effect of the allele that contributes to the development of CD. In fact, in several studies the risk of $\mathrm{CD}$ has been found to be significantly greater in subjects homozygous for the DQB1*0201 allele than in subjects heterozygous for the same allele $[9,10]$. However, both subjects have DQ2 haplotype in the heterozygous state (although with different risk alleles). On the other hand, conflicting data have been published on the gene dose effect and the number of risk alleles on the age of $\mathrm{CD}$ diagnosis and severity of symptoms [11-13].

It is well known that the sensitivity and specificity of HLA genotyping are sufficiently high to exclude CD only when all risk alleles including DQ2 and DQ8 are absent. The ESPGHAN guidelines for the diagnosis and management of CD in children suggest HLA genotyping in asymptomatic children with associated conditions and negative serology. When HLA DQ2/DQ8 is positive, surveillance should continue and serology for $\mathrm{CD}$ should be repeated every three years [3]. On the contrary, when HLA DQ2/ DQ8 is negative, the development of CD is highly unlikely and regular antibody screening may be discontinued [3]. HLA genotyping is also useful in the risk evaluation for CD in 1st degree relatives of patients with CD [14].

In conclusion, we report the development of positive serology for $\mathrm{CD}$ in an asymptomatic child with growth retardation, who previously was evaluated for $\mathrm{CD}$ and had resulted negative. Therefore, when faced with retarded growth in young patients, the paediatric endocrinologist should always maintain a high index of suspicion for $C D$, even if serological markers are negative. Furthermore, in some selected cases with failure to thrive and negative serology for $\mathrm{CD}$, after the exclusion of other malabsorption conditions, the paediatrician could request HLA genotyping, before the intestinal biopsy, in order to check for the presence of risk alleles.

\section{Consent section}

Written informed consent was obtained from the patient's parents for publication of this Case report and any accompanying images. A copy of the written consent is available for review by the Editor-in-Chief of this journal.

\section{Abbreviations}

CD: Celiac disease; HLA: Human leukocyte antigen; SDS: Standard deviation score; BMI: Body mass index; Anti-tTG: Anti-tissue transglutaminase; Ig: Immunoglobulin; FT4: Free thyroxin; TSH: Thyroid stimulating hormone; AGA: Anti-gliadin antibodies.

\section{Competing interests}

The authors declare that they have no competing interests.

\section{Authors' contributions}

MB collected the patient data and drafted the manuscript. EB helped to draft the manuscript. SP helped to collect the data and draft the manuscript. RP and AM participated in the diagnosis and critically revised the manuscript. CM contributed to the interpretation of the data and helped to draft the manuscript. All the authors approved the final version of the manuscript.

\section{Acknowledgement}

The authors are grateful to Laurene Kelly for revising the English of the paper.

\section{Author details}

${ }^{1}$ Internal Medicine and Therapeutics Department, University of Pavia, Fondazione IRCCS San Matteo, Pavia, Italy. ${ }^{2}$ Pediatric and Infectious Disease Unit, Department of Pediatrics, Bambino Gesù Children's Hospital, Rome, Italy.

Received: 7 November 2013 Accepted: 31 December 2013 Published: 15 January 2014

\section{References}

1. Kaukinen K, Partanen J, Mäki M, Collin P: HLA-DQ typing in the diagnosis of celiac disease. Am J Gastroenterol 2002, 97:695-699. 
2. Karell K, Louka AS, Moodie SJ, Ascher H, Clot F, Greco L, Ciclitira PJ, Sollid LM, Partanen J, European Genetics Cluster on Celiac Disease: HLA types in celiac disease patients not carrying the DQA1*05-DQB1*02 (DQ2) heterodimer: results from the European Genetics Cluster on Celiac Disease. Hum Immunol 2003, 64:469-477.

3. Husby S, Koletzko S, Korponay-Szabó IR, Mearin ML, Phillips A, Shamir R, Troncone R, Giersiepen K, Branski D, Catassi C, Lelgeman M, Mäki M, RibesKoninckx C, Ventura A, Zimmer KP, ESPGHAN Working Group on Coeliac Disease Diagnosis, ESPGHAN Gastroenterology Committee, European Society for Pediatric Gastroenterology, Hepatology, and Nutrition: European society for pediatric Gastroenterology, Hepatology, and Nutrition guidelines for the diagnosis of celiac disease. J Pediatr Gastroenterol Nutr 2012, 54:136-160.

4. Meazza C, Pagani S, Laarej K, Cantoni F, Bozzola M: Short stature in children with coeliac disease. Pediatr Endocrinol Rev 2009, 6:457-463.

5. Askling J, Linet M, Gridley G, Halstensen TS, Ekström K, Ekbom A: Cancer incidence in a population-based cohort of individuals hospitalized with celiac disease or dermatitis herpetiformis. Gastroenterology 2002, 123:1428-1435.

6. Maglio M, Tosco A, Paparo F, Auricchio R, Granata V, Colicchio B, Indolfi V, Miele E, Troncone R: Serum and intestinal celiac disease-associated antibodies in children with celiac disease younger than 2 years of age. J Pediatr Gastroenterol Nutr 2010, 50:43-48.

7. Lagergvist C, Dahlbom I, Hansson T, Jidell E, Juto P, Olcén P, Stenlund H, Hernell O, Ivarsson A: Antigliadin immunoglobulin A best in finding celiac disease in children younger than 18 months of age. $J$ Pediatr Gastroenterol Nutr 2008, 47:428-435.

8. Richter T, Bossuyt $X$, Vermeersch $P$, Uhlig HH, Stern M, Hauer A, Zimmer KP, Mearin L, de Roo JH, Dähnrich C, Mothes T: Determination of IgG and IgA antibodies against native gliadin is not helpful for the diagnosis of coeliac disease in children up to 2 years old. J Pediatr Gastroenterol Nutr 2012, 55:21-25.

9. Ploski R, Ascher H, Sollid LM: HLA genotypes and the increased incidence of coeliac disease in Sweden. Scand J Gastroenterol 1996, 31:1092-1097.

10. Arranz E, Telleria JJ, Sanz A, Martin JF, Alonso M, Calvo C, Blanco-Quirós A: HLA-DQA1*0501 and DQB1*02 homozygosity and disease susceptibility in Spanish coeliac patients. Exp Clin Immunogenet 1997, 14:286-290.

11. Congia M, Cucca F, Frau F, Lampis R, Melis L, Clemente MG, Cao A, De Virgiliis S: A gene dosage effect of the DQA $1 * 0501 / D Q B 1 * 0201$ allelic combination influences the clinical heterogeneity of celiac disease. Hum Immunol 1994, 40:138-142.

12. Zubillaga P, Vidales MC, Zubillaga I, Ormaechea V, Garcia-Urkia N, Vitoria JC HLA-DQA1 and HLA-DQB1 genetic markers and clinical presentation in celiac disease. J Pediatr Gastroenterol Nutr 2002, 34:548-554.

13. Karinen $H$, Kärkkäinen P, Pihlajamäki J, Janatuinen E, Heikkinen M, Julkunen R, Kosma VM, Naukkarinen A, Laakso M: Gene dose effect of the DQB1*0201 allele contributes to severity of coeliac disease. Scand J Gastroenterol 2006, 41:191-199.

14. Karinen $H$, Kärkkäinen P, Pihlajamäki J, Janatuinen E, Heikkinen M, Julkunen R, Kosma VM, Naukkarinen A, Laakso M: HLA genotyping is useful in the evaluation of the risk for coeliac disease in the 1st-degree relatives of patients with coeliac disease. Scand J Gastroenterol 2006, 41:1299-1304.

doi:10.1186/1824-7288-40-4

Cite this article as: Bozzola et al:: Late diagnosis of celiac disease in an asymptomatic infant with growth failure. Italian Journal of Pediatrics 2014 40:4.

\section{Submit your next manuscript to BioMed Central and take full advantage of:}

- Convenient online submission

- Thorough peer review

- No space constraints or color figure charges

- Immediate publication on acceptance

- Inclusion in PubMed, CAS, Scopus and Google Scholar

- Research which is freely available for redistribution 